Weight of brain before removal of clots, $1520 \mathrm{gm}$.

Weight of brain after remnval of clots, $1395 \mathrm{gm}$. MICROSCOPICAL DIAGNOSIS.

Cerebral hemorrage (gunshot wound). Gunshot wound of brain. Cerebral softening in frontal lobes. Degeneration of olfactory nerve.

I here insert an extract from a letter recently received from Dr. Miller: "I found significant lesions (excluding the bullet wound, which is described elsewhere) only in the lower frontal regions, i. e., in the under surface of the first convolution immediately external to the longitudinal fissure. The change in the tissue was of the nature of what we call softening or encephalomalacia. Granule cells were present in this area, the presence of such cells indicating that the process was going on for some time. Another evidence of chronicity was the chronic inflammatory changes found in the olfactory nerves, which had also undergone an atrophy. These changes were evidently of traumatic origin, the result of the street-car accident. The mental symptoms were quite consistent with the pathological findings."

Cause of death: Pistol-shot wound of the head and lesions that indicate old inflammation due to former injury, which may have been a cause of mental perversion. The case was reported for inquest.

The boy who shot his father was arrested the night of his father's death and soon released on bail. The next morning he was brought before the First District Court and held without bail for the Grand Jury and remained in jail till the Grand Jury met Feb. 4 to $6,1907$.

The Grand Jury reported "no bill" and he was discharged.

The will of Mr. - - was dated Aug. 20, 1906, nearly a year after the first injury, and at a session of the Probate Court, May 10, 1907, the will was disallowed.

The judge of the First District Court notified me that under the circumstances no inquest was necessary.

\section{A REPORT OF TWO CASES OF POISONING BY WOOD ALCOHOL.*}

hY A. H. PIERCE, M.D., LEOMinster, MASS.,

Associate Medical Examiner.

R. C., was an American about fifty years old, and, except for alcohol addiction, of reasonably good habits.

On Sunday, when drunk, he stole some "Colonial spirits" from the factory where he was employed. Through the day he drank a quantity of it, how much it was impossible to ascertain. He offered some to a friend, who took a few drams only, without disagreeable after-effect.

Monday morning he worked as usual. Monday afternoon he felt sick and remained at home. He complained of headache, dizziness, vomiting, abdominal pains, a burning sensation in epigastrium and behind the sternum, and muscular weakness. He would not allow his wife to call a physician. During the evening he fell into a troubled sleep. He awoke about midnight and found he was totally blind. I visited him about

* Read before the Massachusetts Medico-Legal Society at Boston, Feb. 5, 1908 .
2 A.M. Tuesday; he was in bed, tossing from side to side, complaining bitterly of pain and weakness and nausea and bemoaning his lost vision. His mind was absolutely clear; he told me he "was done for." His skin was pallid and dusky. The pulse was weak and rapid and of poor volume. His respiration was labored, but, as I recall it, not particularly slow. Probably the mental anguish was a factor. Suddenly a severe convulsion occurred and death ensued in a few moments.

No autopsy was performed.

The second case is one in which I was called to investigate and in which, by permission of the district attorney, I performed an autopsy. I quote from my official report:

The clinical history of the case was this: The deceased had had frequent attacks of gastric irritability in the past few years, manifesting themselves by nausea, vomiting, pain in the stomach and prostration. Intemperance in the use of alcohol seemed a sufficient cause for these attacks.

He worked steadily on Dec. 16, 17 and 18, 1906. He was feeling ill on the 17th and was worse on the 18th, complaining of epigastric pain and nausea and great prostration. During the evening of the 18th he became very restless, crying with epigastric pain and expressing his premonition of impending death. At 2.30 A.M., Dec. 19, he asked for a doctor. Dr. E. F. O'Malley, of Fitchburg, responded, reaching the patient at 3.20 A.M. He found him unconscious, but moaning as if in pain, with rapid, feeble pulse, pallid, sweating skin and with pupils widely dilated, but responding equally to light. Under. stimulation his pulse improved, but at 4 A.M. his respiration became very slow (about 5 or 6 to the minute) and a deepening cyanosis preceded a convulsive seizure at 5.30 A.M., followed by a second at 5.40 A.M., ten minutes after which he died. No history of impairment of vision could be elicited.

Subsequent to the autopsy there was obtained from the deceased's wife a bottle of liquid from which he was said to have drunk voluntarily, on Dec. 16, about $1 \frac{1}{2}$ oz., diluting the same with water. No information could be obtained from his family of the source of this bottle. Chemical analysis by Prof. C. F. Nixon proved the liquid to be methyl alcohol, of the quality known as "Colonial spirits."

Autopsy Dec. 19, 9 P.M.: The body was that of a male, well developed and fairly nourished. Apparent age, thirty-four years. Height about 5 feet 8 inches. Hair and moustache dark brown. Rigor mortis and post-mortem lividity of back present. There were three old round scars $\frac{1}{3}$ inch in diameter on the anterior surface of the left leg about 8 inches below the knee.

The usual incisions were made in opening the abdomen, chest and skull.

Abdomen: No excess of fluid in cavity, and peritoneum was normal. Slight swelling of many of the mesenteric glands. Liver, normal in position, size and upon section; spleen, normal; pancreas, normal ; kidneys, normal; ureters, normal; gall bladder, normal excepting a few old adhesions along lower edge.

Appendix: One and one-half inches long, with adhesions and a constriction $\frac{1}{4}$ inch from tip.

Stomach: This organ was tied off at the cardiac and pyloric orifices and its contents, about $4 \mathrm{oz}$., removed through a puncture into a clean jar. The stomach was then laid open. The mucous membrane was decidedly congested, the blood vessels engorged and with numerous hemorrhagic areas of small size.

Intestines: A similar condition extended along the duodenum and the jejunum and a short distance into the ileum, being most intense in the first portion of the duodenum and gradually diminishing in severity until lost. 
Bladder: Normal in position, size and appearance.

Lungs: Numerous old adhesions over right and left upper lobes. Decided congestion of both lower lobes.

Pericardium: About 1 dram of pericardial fluid, a few old fibrinous flakes adherent to visceral and parietal surfaces.

Heart: Empty and normal upon section.

Brain: Dura normal. No increase in cerebrospinal fluid. Blood vessels of pia and subarachnoid space deeply engorged and with hemorrhagic staining of contiguous tissues in many places over cortex. A few adhesions about sylvian fissure near the central fissure. Membranes somewhat dull and grayish.

To recapitulate, there was present moderate gastrointestinal irritation, cerebral congestion, moderate pulmonary congestion and dark, fluid blood.

These two cases give a vivid picture of the clinical aspects of severe methyl alcohol poisoning, viz., vomiting, pain in epigastrium and behind sternum, headache, prostration and disorder of cardiac action and respiration, followed by unconsciousness and death, either with or without convulsions. These are the predominant features in a fatal case. The occurrence of amblyopia is very frequent, but not constant.

In investigating the literature of the last five years upon this subject I find the article of Wood and Buller, in 1904, and later, in 1905 and 1906, the work of C. A. Wood alone, contain all that we know of wood alcohol poisoning. Their viewpoint, however, and, in fact, the viewpoint of almost all writers upon this topic, is that of the medical practitioner and that of the oculist.

From the standpoint of legal medicine little has been written which I could find beyond reports of cases, as, for instance, the very interesting paper of Dr. Hoitt, of Marlboro, a few years ago. So I have been interested in examining the literature of methyl alcohol poisoning for autopsy reports.

C. A. Wood states in 1906 that he has collected 156 fatal cases. I have been able to find accounts of 34 autopsies, the findings of which I have tabulated. This series comprises 21 cases occurring in this country and 13 occurring in Russian Livonia, the cases upon which was based the report of Ströhmberg. These cases, you will recall, followed the drinking, by Russian peasants, of a household remedy in which previously ethyl alcohol was the vehicle. No one knew how many drank of it. However, 13 died and 3 lived in total blindness. The bodies of the 13 who died were examined. The findings as reported by Ströhmberg form the best statement in the literature of the post-mortem appearances in methyl alcohol poisoning and as translated and agreed to by Wood are as follows: Thirteen autopsics. The post-mortem lividity was a livid red, darker than in carbonic oxide poisoning, 12 out of 13 . Rigor mortis well marked (10), goose flesh (10). Face, peculiar cyanotic color; distinct in 5 , not so well shown in 8 . Pupil of medium size in 8 , in. 2 much dilated, in 3 others unaffected. Mucous membrane of lips and mouth unaffected in 10; in 2, whitish. No odor of alcohol on opening cavities in these cases. Blood vessels of mucous membrane, of fauces, larynx and trachea injected. Heart relaxed in 12; in 2 ecchymosed areas on surface. In all instances (13) blood cherry-red, thinner than normal blood, but not quite as thin as the post-mortem fluid blood of asphyxia. Lungs hyperemic and markedly edematous. Stomach and bladder contents not characteristic. Mucosa of stomach hyperemic; in isolated patches in 6 ; ecchymoses in 4 or rose colored throughout; unaffected in 2 cases. Same condition in duodenum. Spleen (12), liver (10), hyperemic. Kidneys: Papillary and cortical substance congested and of dark color. Hyperemic changes of bladder lining, and vessels decidedly injected in 7 cases. Light uniform redness over whole mucosa in 3 other instances. In only one was it of normal appearance. Cerebral vessels filled with blood in all cases. Wood agrees with Ströhmberg that pulmonary edema, the peculiar condition of blood, congestion of brain and mucosa of bladder, post-mortem appearance of skin, isolated areas of injection in stomach, are the characteristic post-mortem appearance.

In view of the thoroughness of Ströhmberg's work we can but discount heavily the statement of so many autopsy reports of negative findings. Such statements as "nothing of importance," "at the base of the brain 2 oz. of water infusion," "findings negative," etc., form a sorry contrast with Ströhmberg's record and almost nullify the value of the reports which contain them. For this reason 4 cases are omitted. Still, in all cases when the stomach and intestines were mentioned, there were found evidences of more or less irritation. In the 30 cases which can be considered at all (4 are absolutely worthless), the dark fluid blood is noted in 22 cases and in none is it contradicted. Next in frequency is the involvement of the lungs, which is noted in 18 cases. In 7 no mention is made and in 5 it is stated that they were negative. The cerebral congestion is mentioned in 15 cases. In 8 no mention is made; in 3 the brain is said to be normal and in 2 there is a question, for instance, in the case with " 2 oz. of water infusion." The unusual condition of the skin, unless expressed by " marked post-mortem lividity," is noted only by Ströhmberg, except that in one of Hoitt's cases there is mention made of this dusky livid appearance of the face. No one in this list notes the unusual appearance of the bladder mucosa except Ströhmberg.

This series of cases is a small one but contains all which could readily be found. It is sufficiently large, however, to define the usual post-mortem appearance in methyl alcohol poisoning and also to point out the moral that observation cannot be too keen and autopsy records cannot be too carefully made. I believe it likely that more careful observation would have shown in my own case that there was slight passive congestion of all the abdominal organs and that the mucosa of the bladder was hyperemic. It will thus be seen that two conditions combine to form this picture. One is a gastro-enteritis of varying severity, the local effect of the poison. The other is a passive congestion of lungs, brain and of various other organs and a peculiar colored fluid blood. The degree of this congestion probably depends on whether 
death was due to asphyxia in convulsions or in light for his work. On returning to work at paralysis of the respiratory centers.

In regard to the bladder's condition I have found no record of cases in this country of any abnormality even where its contents are noted to smell strongly of alcohol. If an error in observation, it is remarkable in the uniformity of its occurrence. Is it not as likely that some other substance in the decoction used in Ströhmberg's cases caused this appearance? It is quite possible that corroborative evidence exists of which I am unaware, since Dr. Wood endorses this statement of Ströhmberg's. The odor of methylated spirits is not infrequently present, it having been noted by one observer in blood, lungs, urine, stomach and brain.

With the free use of denatured alcohol which has just begun in our country, the occurrence of wood alcohol poisoning will become rare again, perhaps as rare as in Great Britain and the Continent, where, until 1904 , only 3 cases were described. So to the future student it will appear that for a period of from fifteen to twenty years there was an epidemic of methyl alcohol poisoning and that a condition very rarely noted previous to 1890 has again become a rarity. In other words, clinical material in this subject will soon be extremely scarce and it should to-day be collected in every possible way.

To resume, the post-mortem appearances are:

1. A hyperemic and usually hemorrhagic condition of the stomach and intestinal mucosa.

2. Dark cherry-red fluid blood.

3. Pulmonary congestion.

4. Cerebral congestion.

5. Hyperemic changes in the bladder mucosa.

6. Peculiar red lividity of skin and dusky facies.

\section{A CASE OF DEATH FROM THE ELECTRIC CURRENT AS A RESULT OF TURNING ON AN ELECTRIC LIGHT.*}

BY FRED E. JONES, M.D.,

Medical Examiner, Quincy, Mass.

THE case I am going to speak of is somewhat similar to the one presented by Dr. Paine, - a case of accidental electrocution, which took place on March 12, 1904. W. S. Junior, the man who was killed, was twenty-one years of age, and worked in a machine shop. He tended a small forge. He stood upon a gravel floor, but the gravel was mixed with considerable iron from the constant chipping of the metal. The forge was made of brick, and about four feet behind the forge was a wooden partition. He ordinarily, and at the time he was killed, stood between the forge and this partition. Over the forge hung a sixteen-candlepower, 110-volt incandescent lamp.

The ordinary incandescent lamp is sixteencandlepower, 110-volts. The candlepower of the lamp may be changed, - it is often ten, eight, six, four, two or one. The voltage is always the same on these ordinary house circuits.

This lamp which he used furnished sufficient

* Read before the Massachusetts Medico-Legal Society. 1 P.M., he apparently reached for his light to turn it on. His sudden cry startled his fellow workmen. They rushed to him. He was then rigid, and his body was extended. He was leaning against the iron bars and the partition behind him. The lamp was attached to the rafters overhead, and was tightly clutched by his hand. The contact being broken, he fell to the floor.

Efforts made to resuscitate him by means of artificial respiration were unavailing. It is supposed that death was instantaneous.

A physical examination showed that he was a well-developed young man, weighed $140 \mathrm{lbs}$, and was five feet eight inches in height. Examination of his hands showed a burn extending from the back into the middle joint of the right forefinger. All the middle joints of the fingers on the back of the hand were burned free of soft tissue.

There is no history of any disease or accident in the past to impair his general health, particularly his heart, as far as could be ascertained. He was a man of good habits, and addicted to no excesses.

An examination of the wires of the building showed two wires which carried to and fro 110 volts of electricity to light the electric lamps. These lamps were hung on cords which tapped the main wire in the rafters. A careful examination showed that though the lights have been installed several years, there was nothing out of order. The fuses were in place at the entrance of the wires into the building, and in each lamp itself.

In explanation I will say that these fuses are made of soft metal, which burns out when a sufficient number of amperes go through them. It is said that the metal, after ageing, becomes less resistant and allows the electricity to flow through without burning it out.

A careful examination of the lamp which he held in his hand was made. An incandescent lamp is screwed into a little brass socket. A current of electricity sufficient to jump through the lamp socket in amount sufficient to kill must have exceeded greatly the 110 volts the wires were supposed to carry.

In the vicinity of the building were wires carrying a higher voltage. The fire alarm and telephone wires carry a low voltage. Street car wires carry a current of over 3,500 volts; and wires from the station to the transformers carry at all times about 2,300 volts.

Under these circumstances, only these last wires at this time of day could have killed this man. The wires from the building led to a transformer several hundred yards distant. This transformer reduces the current of electricity to 110 volts. This 2,300-volt current in some manner was connected accidentally with the 110volt wire. This is a very similar electrocution to the one Dr. Paine has reported.

A professor of electrical science intended yesterday to be here to report the probable cause and possibility of prevention of similar electrocutions. 